Jerzy Szałek

Uniwersytet im. Adama Mickiewicza w Poznaniu

jerzysz@amu.edu.pl

\title{
PRINCIPALES PROBLEMAS METODOLÓGICOS EN LA ENSEÑANZA DEL SUBSISTEMA FONÉTICO-FONOLÓGICO ESPAÑOL EN EL ÁMBITO DE LOS ESTUDIOS UNIVERSITARIOS POLACOS
}

\begin{abstract}
Basic metodological problems in teaching phonetic and phological subsystem of Spanish at the tertiary level of education in Poland
\end{abstract}

The problems concerning teaching methodology in the domain of phonetics and phonology of Spanish have not as yet been properly addressed within the considerably young Polish studies of the Spanish language. The author of the present article, based on his own research and teaching experience, suggests a number of solutions and practical remarks related to teaching methodology of contemporary Spanish phonetics and phonology within Spanish language and literature studies in Poland. The so-called "comprehensive approach" has been verified for compliance with the most recent achievements of modern Spanish phonetic and phonological studies.

Keywords: phonetics and phonology of Spanish, methodology, teaching phonetics, comprehensive approach

Słowa kluczowe: fonetyka i fonologia języka hiszpańskiego, metodologia, fonetyka dydaktyczna, podejście kompleksowe

\section{Algunas cuestiones previas}

De entrada vale la pena hacer una curiosa observación sobre una especie de paradoja que contiene diferentes opiniones de autores sobre la atención que 
se debería prestar al tratamiento de la pronunciación o enseñanza de la fonética y la fonología españolas a la hora de dar clases de español a diferentes etapas de aprendizaje de esta lengua. Véanse al respecto algunas opiniones expresadas p. ej. en Llorente Pinto (2013: 219-250) sobre la importancia de la enseñanza de la pronunciación. "La falta de atención - comenta esta autora - que han mostrado los profesionales de la enseñanza de idiomas hacia la corrección fonética en las últimas décadas contrasta con el interés que suscita este nivel lingüístico en los aprendices. Los estudiantes de idiomas conceden, generalmente, gran importancia al dominio de la pronunciación de la lengua meta» (Llorente Pinto, 2013: 249).

Parecen irreconciliables - y no solo para nosotros - algunas opiniones pseudo-profesionales que se diría enfrentadas entre sí. De un lado debemos inculcar en nuestros futuros filólogos todos los saberes que contienen los modernos programas de estudios, los comunicativos, los interculturales, etc. De otro, se hace caso omiso en el nivel fónico. Teniendo en cuenta una supuesta facilidad de la pronunciación española en comparación con las demás lenguas románicas, cosa bastante controvertida, se suele hacer dejación de su adecuada corrección.

Lo polémico en el tratamiento de la pronunciación de la lengua española ha surgido como consecuencia de varios factores tanto lingüísticos como extralingüísticos que venían apareciendo a medida que se introducía el español como lengua extranjera en los programas escolares de nuestros estudios. Sobre estos condicionamientos vamos a hablar en esta ocasión, tratando de formular en el hispanismo polaco una propuesta de criterios para llevar a cabo una didáctica fonética del español destinada a los profesores polacos de esta lengua (Szałek, 2014a: 243-249). En esta aportación nos limitaremos tan solo al nivel de estudios universitarios, porque tenemos en este campo una experiencia de muchos años de trabajo como fonetista. Al mismo tiempo, nuestro primordial objetivo será señalar algunos problemas típicamente metodológicos, con el fin de ofrecer a los profesores de español polacos algunas pistas y pautas a la hora de impartir clases de fonética o diseñar materiales de diversa índole, imprescindibles en la enseñanza de la pronunciación de la lengua española ${ }^{1}$.

\section{Hacia un curso específico de fonética española para los estudiantes polacos}

En primer lugar, hay que constatar que los primeros pasos de fonética didáctica del español no fueron fáciles, pues al principio los estudiantes de filología

\footnotetext{
${ }^{1}$ Nuestro artículo no se limita tan solo a las advertencias típicamente didácticas, sino sobre todo a los problemas metodológicos más amplios, ligados con el funcionamiento del subsistema fonético-fonológico español.
} 
española en Polonia no disponían de materiales didácticos apropiados y/o grabaciones adecuadas que podían satisfacer las exigencias de estudios universitarios. La situación ha cambiado considerablemente a partir del año 1992, cuando apareció el primer manual de fonética titulado Fonetyka hiszpańska, cuyo autor es Nowikow (editado por la editorial PWN), acompañado de una casete con grabaciones de ejercicios fonéticos interpretados por dos hablantes nativos españoles. Nueve años después, es decir, en 2001, la editorial científica de la Universidad A. Mickiewicz en Poznań editó un método nuevo en español, también a cargo de Nowikow, pero con características un poco diferentes, titulado: Introducción a la fonología y la fonética españolas. Los dos autores, Nowikow y Szałek, lo diseñaron sobre todo, pensando en el estudiante universitario polaco de estudios filológicos. Los objetivos fueron, sin embargo, más amplios que en el caso del manual escrito en polaco, pues los autores del manual consideraron oportuno profundizar en una serie de temas nuevos, sobre todo fonológicos, que parecían adecuados e indispensables para los futuros licenciados en filología española.

Una de las ventajas de estas dos propuestas metodológicas ha sido no solo el hecho de adaptar las materias fonéticas al nivel didáctico de aprendices, sino también confrontarlas con el subsistema fonético-fonológico de su lengua vernácula, es decir, la polaca. La introducción de una gradación de dificultades que tienen los hablantes polacos a la hora de asimilar algunos de los sonidos españoles, así como la de una metodología contrastiva, han permitido enfocar esta propuesta didáctica también hacia los estudiantes con diversos problemas de tipo foniátrico, o sencillamente menos capacitados para aprender lenguas extranjeras. Además, este enfoque metodológico ha tomado en consideración las principales diferencias que existen entre la pronunciación peninsular estándar y la de modalidades diatópicas de Hispanoamérica, o dicho de otra manera, las demás variantes hispánicas. Por otra parte, se introdujo en los dos manuales lo que se suele llamar en la bibliografía lingüística especialidades fonéticas típicamente españolas ${ }^{2}$. Se han tomado

${ }^{2}$ La variación o cambio fonético del español actual toca en algún grado tanto al sistema vocálico como consonántico, así como a la prosodia de todas las zonas dialectales que abarcan diferentes modalidades peninsulares y/o hispanoamericanas. Por otra parte, hay fenómenos fonéticos ligados directamente con lo específico del subsistema fonético-fonológico español que se deben a los procesos diacrónicos de desarrollo, variación y cambio de esta lengua a lo largo de su historia. Consulténse p. ej. (Aguilar, Machuca, 1995: 71-86). Uno de los casos más significativos puede ser p. ej. el fenómeno de la aproximación de algunas consonantes obstruyentes sonoras del castellano moderno (Martínez Celdrán, Fernández Planas 2007, 53-58; Martínez Celdrán 2013, 262-268, Szałek 2008, 267-274). 
en cuenta las nuevas tendencias fónicas que venían apareciendo a lo largo de las últimas décadas en la pronunciación del español en sus diversas variantes, así como algunos fenómenos de variación dialectal, cuyo conocimiento podía resultar muy útil para los que deseaban hablar correctamente en español y entender sus diversas modalidades ${ }^{3}$. Asimismo, se han valorado las dificultades para la adquisición de una pronunciación estándar del español por los estudiantes universitarios ${ }^{4}$, tanto más que el aprendizaje de los principios fonéticos del español se suele apoyar en Europa en la variante estándar, siguiendo las metodologías basadas en la escuela del célebre padre de la fonética española, Tomás Navarro Tomás (1918). Desde la aparición de las primeras ediciones de estos manuales han pasado ya algunos años que influyeron bastante en las metodologías de la enseñanza de la fonética española. Se editaron nuevas ediciones audio-visuales, cada vez más sofisticadas, simulaciones de movimientos articulatorios españoles basadas en programas informáticos ${ }^{5}$, grabaciones de vídeo, etc. Ahora bien, aunque no se puede negar que todos ellos siguen facilitando la obtención de la competencia fónica de nuestros alumnos, sin embargo, no hay que olvidar tampoco el papel decisivo que tiene que desempeñar en el aula el profesor de fonética con sus conocimientos prácticos y teóricos.

En nuestro caso, un curso específico de fonética española bien pensado y elaborado resulta determinante no sólo para introducir en la pronunciación de esta lengua a los que ingresan en la universidad, sino también para que puedan alcanzar, lo más pronto posible, un cierto confort de fluidez fónica que es indispensable para desenvolverse con éxito y soltura, sin trabas, durante todo el curso, dominando a la vez todas las demás destrezas del idioma. Nosotros somos partidiarios y defensores de una metodología compleja en la enseñanza de la pronunciación a este nivel alto de estudios de idioma, es decir, la mixta, combinatoria.

${ }^{3}$ Fíjense p. ej. en la tendencia yeísta en español moderno que actualmente se ha convertido en una pronunciación estándar tanto en la Península Ibérica como en Hispanoamérica. Desde hace tiempo, en nuestras clases de fonética española hemos dejado ya de enseñar la pronunciación de la palatal lateral $/ \lambda /$. La pronunciación de la fricativa palatal sonora / $/$ / tiene hoy en el mundo hispánico carácter mayoritario.

${ }^{4}$ Véanse al respecto toda la serie de publicaciones donde se analizan con más detalle las especialidades fónicas más características de la lengua española actual, así como los modos de afrontarlas por los estudiantes polacos, Szałek (2000: 105-112, 2008: 267-274, 2012: 219-226, 2014a: 243-249 y 2014b: 21-28).

${ }^{5}$ Cf. a modo de ejemplo las animaciones articulatorias de algunos centros de enseñanza del español en EE. UU. (Universidad de lowa: http://www.uiowa.edu/ aca dtech/phonetics/spanish/spanish.html DW 21.03.2015). 


\section{Propuestas de otras metodologías}

En este lugar, valdría la pena mencionar algunas propuestas de otras metodologías fonéticas que encontramos en la actual bibliografía didáctica española. A modo de ejemplo, pueden ser de mucha utilidad algunas pistas y análisis formulados, no hace mucho tiempo, por una de las más prestigiosas especialistas españolas en materia de fonética didáctica, Gil Fernández (2007). Su valioso y exhaustivo trabajo sobre la enseñanza de la pronunciación de lenguas extranjeras puede ofrecer muchas soluciones al profesor universitario polaco a la hora de preparar sus propias estrategias para las clases de fonética, aunque va dirigido a diferentes niveles de estudio, incluidos los de E.L.E. Vamos a mencionar en esta ocasión tan solo algún detalle de su larga e interesante exposición. Después de haber escrito algunos métodos clásicos, más o menos independientes, como el articulatorio, los audiolingüísticos, el comunicativo y el de nuevas tecnologías, la autora trata de dar un resumen de las ventajas e inconvenientes de algunos recursos o procedimientos para enseñar la pronunciación española, p. ej. descripciones articulatorias, empleo de la transcripción fonética, empleo de recursos audio-visuales, práctica de las oposiciones fonológicas, enseñanza comunicativa, etc. (Gil Fernández, 207: 126-152).

En este trabajo, sin embargo, trataremos de poner de manifiesto algunas de las pautas que hemos podido proponer y verificar nosotros mismos impartiendo durante muchos años clases de fonética y fonología españolas a nivel de estudios universitarios polacos. Destacaremos lo que nos parece específico e importante en la enseñanza de la fonética española en este grado de estudio, así como trataremos de dar, en la medida de lo posible, algunos consejos prácticos que pueden ser de utilidad en la clase de fonética específica. No dejaremos tampoco de apoyarnos en la manera de confeccionar los métodos (manuales) señalados anteriormente.

\section{El enfoque complejo o combinatorio en fonética universitaria}

No cabe duda de que a nivel de estudios universitarios debemos compaginar los conocimientos prácticos con los teóricos. Un diplomado o licenciado en filología española debe conocer lo suficientemente bien los fundamentos teóricos y prácticos tanto de fonética, materia lingüística externa, como de fonología, disciplina lingüística interna. Hay que mencionar que los programas de estudios de filología española en nuestro país abarcan diversas materias, entre las cuales hay muchas horas de español práctico como lengua extranjera, impartidas por diferentes hablantes nativos que, no obstante, no pronuncian el idioma español de la misma manera, lo que quiere decir, que, a menudo, 
provienen de distintos países de habla española. Por supuesto, esa circunstancia no nos ayuda, ni mucho menos, para llevar a cabo un curso de fonética universal y equilibrada. Además, el curso dura en los estudios polacos tan sólo un semestre, lo que se traduce en dos horas lectivas de fonética a la semana. No cabe duda de que en las clases de español práctico E.L.E. hay que seguir una metodología algo modificada que podrá comprobar y aprovechar las destrezas y los conocimientos adquiridos por los estudiantes durante el curso específico de fonética. Frente a la diversidad y complejidad de modos de hablar en español actual optamos por la pronunciación de la variante estándar, con algunas excepciones que se deben a algunas tendencias actuales en la pronunciación panhispánica, considerando, que la variante castellana está presente en casi todas las modalidades cultas de los países hispanoamericanos, que, como es sabido, tienden hoy hacia las normas fónicas propias de sus capitales. Desde luego, siguiendo las recomendaciones académicas, no podemos perder también de vista la antes señalada variación fónica panhispánica, así como algunas tendencias actuales en los modos de hablar en español, pues todas juntas constituyen una base común para el entendimiento de todos los hispanohablantes, que actualmente alcanzan en el mundo casi quinientos millones de personas (RAE, AALE, 2011).

El enfoque complejo o combinatorio en fonética universitaria supone el aprovechamiento de los últimos éxitos en todas las ramas fonéticas y/o metodologías fonológicas modernas (Penas Ibáñez, 2013). Creemos que vale la pena incluir en nuestros procedimientos metodológicos elementos de fonética acústica y experimental, utilizando en clase oscilogramas, espectros, sonogramas y demás gráficos que parecen indispensables si deseamos resolver satisfactoriamente muchas dudas que conlleva la enseñanza de la articulación de un idioma. Estas incertidumbres surgen cuando comparamos algunos sonidos polacos con sus equivalentes españoles, que son aparentemente idénticos con los polacos, p.ej. los alófonos aproximantes españoles $[\beta],[\delta]$, $[\gamma]$ con los alófonos oclusivos polacos [b], [d], [g]. El problema en fonética no es, sin embargo, en muchos casos, articulatorio, sino más bien perceptivo, es decir auditivo. Por eso, hay que dedicar especial atención a los patrones entonativos de la lengua española que difieren considerablemente de sus respectivos modelos polacos. Desde 2011, disponemos de algunos programas informáticos fonético-interactivos que contienen muestras de las entonaciones de todo el ámbito hispánico. Las voces del español, en forma de anejo a la Nueva gramática de la lengua española. Fonética y fonología (RAE, AALE,

\footnotetext{
${ }^{6}$ Sin embargo, vale la pena comentar también que en nuestro trabajo no despreciamos a ninguna de las prestigiosas modalidades fonéticas españolas en Hispanoamérica.
} 
2011) ofrecen al profesor de fonética una herramienta de primera índole. Este DVD, elaborado en colaboración con las veintidós academias de la lengua española, permite comparar los sonidos y escuchar melodías de hablas españolas tal como se oyen hoy en día en todas las zonas hispánicas.

\section{La disposición articulatoria del español: precisiones y/o consejos prácticos}

Las precisiones articulatorias pueden ser también muy útiles en fonética universitaria, porque permiten resolver algunas vacilaciones si una persona tiene p.ej. problemas auditivos y desea, a pesar de los pesares, llegar a pronunciar como un nativo. Un buen ejemplo lo tenemos con la africada palatal sorda española /c/y las africadas polacas: palatal sorda mediolingual /to/ y la alveolar predorsal sorda / $\mathrm{t} /$ (Nowikow, Szałek, 2001: 55-56). En este sentido, son asimismo de mucha utilidad las imágenes articulatorias que se obtienen hoy mediante resonancia magnética. Por ejemplo, las fricativas españolas se realizan hasta en seis lugares de articulación, es decir, labiodental, dental, interdental, alveolar, palatal y velar. Gracias a estos modelos visuales podemos señalar con precisión donde se produce la constricción al pronunciar cada una de estas consonantes. Es obvio que las descripciones articulatorias no pueden ser exclusivas a la hora de enseñar fonética, pues, como señala la autora antes citada (Gil Fernádez, 2007: 142-143), no toman en cuenta el factor auditivo y la prosodia. Los efectos de la coarticulación de los sonidos que se revelan en forma de asimilaciones en la cadena hablada tampoco se explican a través de esquemas articulatorios. Sea lo que sea, son imprescindibles desde el punto de vista teórico-práctico y en este nivel de estudio que comentamos, no se puede renunciar a ellos. En cuanto al empleo de la transcripción fonética (que es distinta de la fonológica) como modo de aprender bien la fonética, hay que hacer en este lugar unas cuantas advertencias, más prácticas que teóricas. En el caso del español, teniendo en cuenta un cierto acercamiento fónico-gráfico de esta lengua con el polaco, lo recomendable sería optar por un sistema lo menos complicado y desarrollado. En la mayoría de los casos adoptamos un sistema semiestrecho ${ }^{7}$, que no toma en cuenta el grado de abertura y cierre de las vocales, y siendo el más extendido, contiene todos los alófonos que son imprescindibles en el aprendizaje de la pronunciación española. Es evidente que el alfabeto fonético no tiene que ser para los estudiantes un arte por el arte, lo utilizamos solamente para indicar principales diferencias entre las grafías y los fonos. Hay que ser consciente de que el manejo de estos signos abstractos tiene, especialmente en el

\footnotetext{
${ }^{7}$ Los detalles sobre sistemas de transcripción y simbologías fonéticas recomendables se pueden consultar en (Nowikow, Szałek, 2001: 23-26).
} 
caso del alumno polaco, función auxiliar (adicional). La práctica fonética en el aula demuestra que el conocimiento y uso de signos fonéticos no puede sustituir la difícil tarea de búsqueda por parte de nuestros alumnos de una nueva base de articulación, la de la L2. Dicho en otros términos, no sugerimos al profesor de fonética española concentrarse a toda costa en el uso del alfabeto fonético, sino en lo auditivo. En nuestra opinión, los docentes de fonética deben, en primer lugar, tratar de familiarizar a los discentes con los auténticos sonidos y curvas melódicas del idioma meta, aprovechando todos los recursos que están a su disposición. La calidad de las grabaciones que se utilizan en el aula tiene que ser una prioridad. Aconsejamos evitar muestras fonéticas que contienen los vicios fónicos de lectores que se deben a la interferencia de sus variedades diatópicas, por ejemplo, a la influencia catalana en el castellano. Los catalanes suelen abrir las vocales tónicas y neutralizar las átonas o sonorizar la consonante /s/ en posiciones intervocálicas. La consonante aproximante dental so-

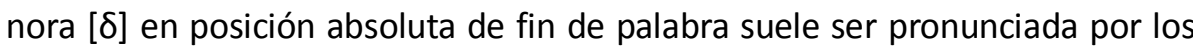
hablantes catalanes del español con bastante tensión, como la dental sorda $[\mathrm{t}]^{8}$.

Antes de empezar la clase de fonética española sería preciso darse cuenta del hecho de que el español es una lengua de tendencia central anterior, lo que quiere decir que en esta lengua se habla más por delante que por detrás, ensanchando un poco la boca en las comisuras de los labios. En comparación con el polaco, la disposición articulatoria de la lengua española se caracteriza por un grado de tensión muscular relativamente más alto, lo que se transmite en los movimientos articulatorios más precisos tanto del ápice lingual como del postdorso de la lengua. Aunque la duración de las vocales castellanas no cambia y todas son cortas, deben ser pronunciadas como tensas. En comparación con otras lenguas románicas, el español no reduce las vocales inacentuadas ${ }^{9}$. Por fines didácticos, no tomamos en cuenta los supuestos alófonos vocálicos españoles que según el grado de abertura distinguió, hace tiempo, NavarroTomás (1918 [1977]). Este autor, como se sabe, clasificaba variantes abiertas y cerradas en las vocales altas y medias y las anteriores en la vocal baja central /a/. Los estudios más recientes, ante todo, de fonética experimental (p.ej. los de electropalatografía) no han confirmado tal distinción contextual ${ }^{10}$.

8 Por supuesto, hay más interferencias catalanes en el español, no obstante, los hablantes catalanes que conocen bien ambas lenguas suelen, por lo general, evitar tales desajustes fónicos (cf. p. ej. García Mouton, 1996).

${ }^{9}$ Sobre la base de articulación española se puede consultar un extenso capítulo en (Gil Fernández, 2007: 185-259).

${ }^{10}$ Véanse al respecto, Martínez Celdrán y Fernández Planas, (2007), Fernández Planas, (2013). 
Para resumir lo que hemos dicho sobre los ajustes articulatorios generales característicos del castellano, merece la pena citar lo que señala Gil Fernández (2007: 230):

«- tensión articulatoria relativamente alta,

- fonación modal, laringe en posición neutra (sin descenso ni elevación marcados),

- resonancia central - ligeramente anterior,

- escasa labialización (redondeamiento labial no muy marcado),

- considerable actividad del ápice de la lengua,

- desplazamiento mandibular marcado,

- escaso grado de nasalidad». (op.cit.).

La metodología fonética que proponemos supra debe compartir, en la medida de lo posible, las similitudes y/o diferencias articulatorias entre la lengua española y la polaca. Las sutilezas fónicas hay que detectarlas desde la primera clase de fonética, dedicada por lo general al sistema vocálico. Los primeros ejercicios realizados después de escuchar las grabaciones nativas han de suponer un cambio de tensión articulatoria por parte de nuestros alumnos. Al mismo tiempo, lo útil y provechoso sería introducir los llamados ejercicios de contraste con la lengua vernácula. Para conseguir una adecuada tensión articulatoria en los sonidos españoles hay que evitar a toda costa los alargamientos (cambio de duración) y el aumento de intensidad. Al contrario, la atención de los discentes ha de ser encaminada hacia los músculos de la lengua y las mejillas, así como en sílaba acentuada, que preponderantemente es abierta en español, y por eso, hace falta pronunciarla con más fuerza. Por si fuera poco, tenemos que introducir inmediatamente las llamadas actividades antipalatizantes, que parecen de mucha importancia si queremos sonar igual que los nativos. En la lengua española percibimos las siguientes combinaciones de sonidos que no se palatalizan: [ni], [li], [bi]], [gui],[di]. La palatalización por el contrario es propia del polaco, p. ej. en palabras polacas del tipo: biec, lina, litr, biel, giętki, niania, etc. Las palabras españolas como p. ej.: [níno] niño, [ninería], niñería, [nináto] niñato, se pronuncian con mucho cuidado sin palatizar la [n] en la primera sílaba.

\section{A modo de conclusión}

En la lengua española moderna existen dos subsistemas principales de pronunciación: el llamado subsistema seseante, que no distingue la consonante fricativa interdental sorda $/ \theta /$ y la que sustituye por la $/ \mathrm{s} /$ predorsal, y el subsistema distinguidor, en el que se pronuncian la /s/ fricativa ápicoalveolar 
sorda y la fricativa interdental sorda $/ \theta /$. A decir verdad, el sistema distinguidor se reduce solo al territorio peninsular español, sin contar Andalucía ${ }^{11}$. De esta manera, en nuestras actividades en la clase estamos obligados a explicar las diferencias en la pronunciación de las dos principales /s/ españolas ${ }^{12}$. Hay que advertir que no se puede hacer tan solo por la descripción articulatoria, sino que en este caso sería más conveniente acudir a la metodología de la fonética experimental, explicando los respectivos sonogramas de la /s/ predorsal y la /s/alveolar, respectivamente. La Real Academia de la Lengua Española admite la pronunciación de las dos $/ \mathrm{s} /$ españolas indistintamente y por eso, no hace falta insistir en la preferencia del uso de una variante por la otra. La variante alveolar es más difícil de conseguir para un estudiante polaco, lo que demuestra la práctica, sin embargo, es que un futuro filólogo hispanista debería por lo menos saber reconocer el modo de su articulación.

Desde el punto de vista fonológico, en nuestros métodos de fonética destinados para estudiantes extranjeros valdría la pena prestar más atención a la geometría de los rasgos distintivos que forman parte de las representaciones fonológicas del español, que han sido presentadas últimamente con detalle en (RAE, AALE, 2011). Estos permiten comprender mejor el funcionamiento del subsistema fonético-fonológico español actual, especialmente si tenemos que analizar los puntos potenciales de variación fonética en las diferentes partes de la zona articulatoria, es decir, labial, coronal y dorsal.

Los manuales que utilizamos en nuestra práctica diaria necesitarían pues, en nuestra opinión, algunos retoques, complementaciones y/o actualizaciones, lo que hoy nos parece evidente. En Nowikow, Szałek (2001) hemos descrito tan sólo un archifonema del sistema fonológico español, es decir, el /R/. En Quilis (1997), para dar otro ejemplo de manual, se incluyeron algunos archifonemas más, bien característicos para el español actual: los de /N/, /B/, /D/, /G/. Estos archifonemas son resultado de las neutraliza ciones (ausencia de oposiciones) de los respecitvos fonemas en la posición implosiva o postnuclear de la sílaba, lo que influye decisivamente en la distribución de diversos alófonos en esa posición de la sílaba española.

\footnotetext{
${ }^{11}$ La situación fonética en Andalucía es aún más compleja, porque se distinguen allí tanto zonas seseantes como ceceantes, así como intermedias.

12 En todo el ámbito español, como es sabido, hay más variantes de /s/. La /s/ del seseo resulta polimórfica y desde los estudios de Canfield (1962) se registran en Hispanoamérica, por lo menos, sus 4 variantes (Vaquero de Ramírez, 1996). Además, hay que recordar también que la /s/ española en posición implosiva (postnuclear) en algunos territorios puede aspirarse o hasta perderse. Desde el punto de vista normativo, este tipo de modos de articulación son considerados como dialectales (Nowikow, Szałek, 2001: 71-72).
} 
En resumen, en este artículo hemos tratado de dar una visión generalizada de problemática metodológica fonética española, respaldada en nuestra larga experiencia de trabajo en el auditorio fonético universitario, que suponemos puede ser de alguna utilidad tanto para docentes como discentes de la fonética y fonología españolas a nivel de estudios de filología española en Polonia. Somos conscientes de que en realidad no existen metodologías completas y/o perfectas que sean universales y únicas para todas las etapas de aprendizaje de idiomas como segunda lengua. Nuestras proposiciones y advertencias, por motivos obvios, debidos al reducido espacio de este artículo, tienen carácter más orientativo que exhaustivo. Como es sabido, el subsistema fonético-fonológico del español, segmental y suprasegmental, es objeto de diversas presentaciones y estudios pormenorizados en los manuales y trabajos monográficos actuales, por lo que no hacía falta hacer descripciones técnicas detalladas de su contenido. Nos hemos limitado tan sólo a los problemas típicamente metodológicos, teniendo en cuenta la especificidad del contraste fonético que hay entre las dos lenguas, la española y la polaca, así como la falta de bibliografía didáctica fonética en el área de estudios hispánicos polacos.

\section{BIBLIOGRAFÍA}

Aguilar, L., Machuca, M. J. 1995. «Procesos fonéticos en el español actual y su relación con fenómenos diacrónicos: debilitamiento de obstruyentes, asimilación de consonantes contiguas y procesos de monoptongación». In: Lingüística española. Aspectos sincrónico y diacrónico. Estudios Hispánicos (red. Nowikow, W.). Wrocław: Wydawnictwo Uniwersytetu Wrocławskiego IV, 71-86.

Canfield, D. 1962. La pronunciación del español en América. Bogotá: Instituto Caro y Cuervo. Fernández Planas, A. M. 2013. «Fonética acústica y experimental. Las vocales. Las glides y las consonantes sonantes en la cadena hablada». In: Panorama de la fonética española actual. (red. Azucena Penas Ibáñez, M.). Madrid, Arco Libros: 291-320.

García Mouton, P. 1996. Lenguas y dialectos de España. Madrid: Arco Libros.

Gil Fernández, J. 2007. Fonética para profesores de español: de la teoría a la práctica. Madrid: Arco Libros.

Llorente Pinto, M. del Rosario. 2013. «La importancia de la enseñanza de la pronunciación». In: Panorama de la fonética española actual, (red. Azucena Penas Ibáñez, M.). Madrid: Arco Libros: 229-252.

Martínez Celdrán, E., Fernández Planas, A. M. 2007. Manual de fonética española. Articulaciones y sonidos del español. Barcelona: Ariel Lingüística.

Martínez Celdrán, E. 2013. «Fonética acústica y experimental. Los sonidos obstruyentes en la cadena hablada». In: Panorama de la fonética española actual. (red. Azucena Penas Ibáñez, M.). Madrid: Arco Libros: 253-289. 
Navarro Tomás, Tomás, 1977 [1918]. Manual de pronunciación española. Madrid: CSIC.

Nowikow, W. 2012 [1992, 1996]. Fonetyka hiszpańska. Warszawa: Wydawnictwo Naukowe PWN.

Nowikow, W., Szałek, J. 2001. Introducción a la fonología y la fonética españolas. Poznań: Wydawnictwo Naukowe UAM.

Penas Ibáñez, M. A. (ed.) 2013. Panorama de la fonética española actual. Madrid: Arco Libros.

Quilis, A. 1997. Principios de fonología y fonética españolas. Madrid: Arco Libros.

RAE, AALE, 2011. Nueva gramática de la lengua española. Fonética y fonología. Barcelona: Espasa Libros.

Szałek, J. 2000. «Dificultades para la adquisición de una pronunciación estándar del español por los estudiantes universitarios». In: 25 Aniversario de la Cátedra de Estudios Ibéricos, Universidad de Varsovia. Memorias del Simposio Internacional, 8-10 de octubre de 1997 (red. Małcużyński, M.- P.). Itinerarios 3/2, 105-112, Varsovia: Universidad de Varsovia.

Szałek, J. 2008. «Las aproximantes españolas, entre la teoría y la práctica». Studia Romanica Posnaniensia 35: 267-274.

Szałek, J. 2012. "La "troica fonética castellana" o trío de fonemas castellanos más típicos». Neophilologica 24: 219-226.

Szałek, J. 2014a. «Criterios de diseño de una didáctica fonética del español para profesores de lengua polacos». In: Lingüística española en Polonia: líneas de investigación (red. Pawlik, J., Szałek, J.). Poznań: Wydawnictwo Naukowe UAM: 243-249.

Szałek, J. 2014b. "Las consonantes róticas españolas a la luz de las últimas investigaciones fonológicas, fonético-articulatorias y acústicas». In: Variación, contraste, circulación. Perspectivas lingüísticas en el hispanismo actual (red. Bułat Silva, Z., Głowicka, M., Wesoła, J.). Wrocław: Wydawnictwo Uniwersytetu Wrocławskiego: 21-28.

Vaquero de Ramírez, M. 1996. El español de América I. Pronunciación. Madrid: Arcos Libros. http://www.uiowa.edu/ acadtech/phonetics/spanish/spanish.html [fecha de consulta: DW 21-03-2015]. 